\title{
3 Research Square

\section{Impact of Endovascular Treatment on Leg Muscle Mass in Peripheral Artery Disease: a Preliminary Report}

\section{Tomoyo Miyakuni}

Nihon Ika Daigaku Chiba Hokuso Byoin

Hidenori Komiyama ( $\nabla$ h-komiyama0317@nms.ac.jp )

Nihon Ika Daigaku https://orcid.org/0000-0002-1995-8388

Masamichi Takano

Nihon Ika Daigaku Chiba Hokuso Byoin

Takeshi lkeda

Nihon Ika Daigaku Chiba Hokuso Byoin

Masato Matsushita

Nihon Ika Daigaku Chiba Hokuso Byoin

Nobuaki Kobayashi

Nihon Ika Daigaku Chiba Hokuso Byoin

Yasushi Miyauchi

Nihon lka Daigaku Chiba Hokuso Byoin

Kuniya Asai

Nihon Ika Daigaku Chiba Hokuso Byoin

Yoshihiko Seino

Nihon Ika Daigaku Chiba Hokuso Byoin

Wataru Shimizu

Nihon Ika Daigaku

Original investigation

Keywords: Endovascular treatment, ischemia, peripheral arterial disease, thigh muscle area

Posted Date: April 15th, 2020

DOl: https://doi.org/10.21203/rs.3.rs-21826/v1

License: (c) (i) This work is licensed under a Creative Commons Attribution 4.0 International License.

Read Full License 


\section{Abstract}

Background: Peripheral artery disease (PAD), intermittent claudication, and impaired mobility lower patients' quality of life, contributing to the loss of skeletal muscle. This study sought to investigate the impact of endovascular treatment (EVT) by measuring the mid-thigh level of muscle volume in above the knee PAD patients before and after EVT.

Methods: In this prospective, observational study, symptomatic PAD patients with above the knee lesions who had intermittent claudication and were undergoing optimal medical treatment were enrolled. The midthigh level of muscle area was measured by computed tomography initially, and then 3 and 6 months after EVT. Patients were categorized into ipsilateral or bilateral based on clinical symptoms and initial ABI value. The muscle area in ischemic and non-ischemic legs were compared in ipsilateral PAD patients. The correlations between alterations in the total thigh muscle area and clinical characteristics were analyzed in univariable and multivariable analysis to investigate the factor contributing skeletal muscle loss.

Results: A total of 22 patients were analyzed. The muscle area of the thighs increased after EVT. Fourteen patients had ipsilateral lesions and 8 had bilateral stenosis. In patients with ipsilateral lesions, the midthigh muscle area of ischemic lower limbs was significantly lesser than that of non-ischemic lower limbs $\left(118.2 \pm 16.5 \mathrm{~cm}^{2}\right.$ vs $\left.124.0 \pm 17.3 \mathrm{~cm}^{2}, \mathrm{p}=0.0002\right)$. The thigh muscle area of ischemic lower limbs increased after EVT (before: $118.2 \pm 16.5 \mathrm{~cm}^{2}$ vs 3 months: $124.0 \pm 18.7 \mathrm{~cm}^{2}, \mathrm{p}=0.0166$; before vs 6 months: $\left.123.0 \pm 17.7 \mathrm{~cm}^{2}, \mathrm{p}=0.0566\right)$, but this was not the case for non-ischemic lower limbs. Multivariate regression analysis revealed that baseline glycated hemoglobin was the only factor that negatively correlated with the change in the muscle area after $3(\beta=-3.74,95 \%$ confidence interval $[\mathrm{Cl}]=-7.3$ to -0.2 , $p=0.0417)$ and 6 months $(\beta=-5.24,95 \% \mathrm{Cl}=-10.1$ to $-0.4, p=0.03567)$. Muscle area significantly increased in normoglycemic $\mathrm{HbA} 1 \mathrm{c}<6.5$ patients (before: $246.1 \pm 33.5 \mathrm{~cm}^{2}$, before vs 3 months: $249.6 \pm 34.6 \mathrm{~cm}^{2}, \mathrm{p}=$ 0.032 , before vs 6 months: $250.6 \pm 35.7 \mathrm{~cm}^{2}, p=0.0455$ ) while there was no significant alternation in hyperglycemic $(\mathrm{HbA} 1 \mathrm{c} \geq 6.5)$ patients (before: $225.2 \pm 43.4 \mathrm{~cm}^{2}, 3$ months: $224.6 \pm 44.8 \mathrm{~cm}^{2}, 6$ months: $\left.222.2 \pm 45.5 \mathrm{~cm}^{2}\right)$.

Conclusions: Ischemia induces muscle atrophy in PAD patients. However, ischemic muscle atrophy was ameliorated after EVT in normoglycemic patients. There is a need for large scale trial to investigate the impact of EVT if it would protect or even delay skeletal muscle loss in all-comer population.

\section{Background}

Skeletal muscle loss is a growing field that is gaining attention among medical researchers [1]. Patients with diabetes tend to have excessive loss of skeletal muscle in comparison with non-diabetic patients[2]. Atherosclerosis in the lower-limb peripheral arteries in patients with diabetes, dyslipidemia, and hypertension lead to peripheral arterial disease (PAD) $[3,4]$ where reduced blood flow to the lower-limbs can induce metabolic myopathy of muscle in the diseased lower limbs [5] contributing to further skeletal muscle loss. The regional thigh muscle measurement is correlated with whole body skeletal muscle mass, 
implicating the role of thigh muscle loss as a surrogate of clinical fragility[6]. Additionally, the thigh muscle area, as measured by computed tomography (CT), can be a predictor of mortality [7]. A recent study showed that the proximal lesion location in PAD was associated with a poorer prognosis than that in the distal lesion location, presenting a negative association between lesion location and the volumetric area of muscle blood supply [8]. As per the current clinical guidelines, endovascular treatment (EVT) is considered if the symptoms of patients with PAD persist after undergoing guideline-based medical treatment [9]. Assessment of the disease status utilizing only the cross-sectional single-slice CT measurements was associated with muscle volume for the identification of atrophy and focal sarcopenia [10]. Therefore, in this preliminary study, we measured the muscle volume at the mid-thigh level in PAD patients with above the knee lesions before and after EVT to investigate the impact of EVT on patients with PAD.

\section{Methods}

\section{Study Design}

This was a single-center prospective observational study. Consecutive PAD patients with intermittent claudication under guideline derived pharmaco-physiological therapy who were scheduled to undergo elective EVT were enrolled. Patients who do not obey smoking prohibition, requiring maintenance hemodialysis, with critical ischemia or infection were excluded. The Institutional Review Board of the hospital reviewed and approved this study. This study had been performed in accordance with the Declaration of Helsinki obtaining informed consent from all patients.

\section{Endovascular Treatment}

Patients who were intolerant to certain medications or contrast agents did not participate in the study. Dual antiplatelet therapy was administered to all patients for at least 7 days before EVT. At the start of the procedure, weight-adjusted intravenous heparin was administered with a target activated clotting time of $>300 \mathrm{~s}$. After crossing the guidewire through the target lesion, dilatation of the lesion was performed using a suitable balloon size. Stent placement was performed if flow limitation or residual stenosis $>30 \%$ of elastic recoil remained in the target vessel. Twenty-one patients received stent placements. The size of the balloons was decided by the operator and the stents exceeded the reference diameter by $1 \mathrm{~mm}$. Postdilatation was performed by a balloon shorter than the stent. Although efforts were made to finalize the procedure with a single stent placement, multiple stents were placed to achieve $<30 \%$ residual stenosis in the target lesion. The stents that were used were EPIC (Boston Scientific, Massachusetts), and SMART (Cordis Co, Florida).

\section{Measurement of Thigh Muscle Area}

A CT scan of the thighs was performed with a 64-slice Toshiba Aquilion 64 system (Toshiba Medical Systems, Otawara, Japan) [11]. The thigh muscle area was measured by a commercial workstation (SYNAPSE; Fujifilm, Tokyo, Japan); further, the thigh muscle area was measured for both legs at the cross section of the midpoint of the upper margin of the distance between the upper edge, the midpoint of the 
upper margin of the greater trochanter and the lower margin of the femoral condyles; and the lower edge, the midpoint of the upper margin of the patella and the lower margin of the patella (Figure 1) [7]. The investigators (TM and HK) who conducted the measurements were blinded to patients' clinical and laboratory data.

\section{Ankle-Brachial Index Measurement}

The ankle-brachial index (ABI) was measured using a Colin Wave-form analyzer (BP-203RPE III; Omron Colin, Tokyo, Japan), according to the recommendations of the American Heart Association [12]. The ABI was measured at the time of admission and at discharge, as well as after 3 months and 6 months.

\section{Statistical Analysis}

Categorical data are presented as the frequency (percentage), and continuous variables are expressed as means \pm standard deviations (SDs), as well as medians with inter-quartile ranges. All the statistical analyses were performed with R@ (Ver 3.6.2, R Foundation for Statistical Computing, Vienna Austria). The Shapiro-Wilk test was used for assessing whether variables were normally distributed, and the Chi-square test was used for dichotomous variables. The mid-thigh area pre, 3 months post, and 6 months post EVT were compared by paired t-tests. The univariable and multivariable regression analyses between the change in (delta) the area of the thighs after 3 or 6 months and the baseline patient characteristics including the lesion location (bilateral), female sex, $\mathrm{HbA} 1 \mathrm{c}$, age, body mass index (BMI), Rutherford classification, hypertension, dyslipidemia, chronic kidney disease (CKD), and smoking history were performed to identify the baseline characteristics associated with the delta muscle area by the use of the MASS package ('Modern Applied Statistics with S', 4th edition, 2002). The quality of linear prediction models were assessed by the gvlma (Global Validation of Linear Models Assumptions) package [13]. Statistical power analyses were evaluated with pwr (Basic Functions for Power Analysis) package [14].

\section{Results}

Patients were registered from 2016 to 2019. A total of 22 lower extremity PAD patients with above the knee lesions were enrolled (Figure 2). If the patient had an abnormal $A B I$ value $(\leq 0.90)$ on one side and had the symptom in the same leg, this was defined as a patient with an ipsilateral lesion. The characteristics of each patient are summarized in Table 1. The patients' mean age was $72.4 \pm 7.4$ years, and male sex (91\%), hypertension (82\%), and dyslipidemia (86\%) were prevalent. Baseline clinical symptoms were classified based on the Rutherford classification of PAD; category $1(n=11,50.00 \%)$, category $2(n=10,45.45 \%)$, and category $3(n=1,4.55 \%)$. All patients received dual antiplatelet therapy before EVT. The ABI value was improved in diseased lower limbs and maintained throughout the study period (30 ischemic lower limbs: before $0.79 \pm 0.14,3$ months $1.08 \pm 0.13,6$ months; $1.06 \pm 0.16,14$ non-ischemic lower limbs: before $1.01 \pm$ $0.10,3$ months $1.03 \pm 0.12,6$ months; $1.05 \pm 0.14$ ). Clinical symptoms were improved after EVT and maintained during the study period; 3 months: category 0 [91 \% $(n=20)]$, category 1 [9\% $(n=2)] ; 6$ months: category 0 [82\% $(n=18)]$, category $1[18 \%(n=4)]$. Lesion characteristics are summarized in Table 2 . Sixteen (53\%) lesions were located in the iliac artery, 9 (30\%) in the superficial femoral artery, $1(3 \%)$ in 
the common femoral artery, $3(13.6 \%)$ in the popliteal artery, and 1 (3\%) in both the superficial and popliteal artery. All patients were successfully discharged the day after EVT without any complications.

\section{Change of the Thigh Muscle Area}

The muscle area of the thigh increased after EVT (before: $240.4 \pm 36.6 \mathrm{~cm}^{2}, 3$ months: $242.8 \pm 38.2 \mathrm{~cm}^{2}, 6$ months: $242.8 \pm 39.6 \mathrm{~cm}^{2}$ ) (Figure 3).

In ipsilateral PAD patients, the mid-thigh level of the thigh muscle area of ischemic lower limbs $(n=14)$ was significantly smaller than the area in non-ischemic lower limb (ischemic lower limbs: $118.2 \pm 16.5 \mathrm{~cm}^{2}$ vs non-ischemic lower limbs: $124.0 \pm 17.3 \mathrm{~cm}^{2}, \mathrm{p}^{\star}=0.0002$ ) (Figure 4). The thigh muscle area in ischemic lower limbs ( $n=14$ ) increased after EVT (before vs 3 months: $121.4 \pm 16.3 \mathrm{~cm}^{2}, \mathrm{p} \dagger=0.0166$; before vs 6 months: $120.9 \pm 16.1 \mathrm{~cm}^{2}$, pt+ $\left.=0.0566\right)$, whereas the area did not increase in non-ischemic lower limbs ( $\mathrm{n}$ = 14; before: $124.0 \pm 17.3 \mathrm{~cm}^{2}, 3$ months: $124.0 \pm 18.7 \mathrm{~cm}^{2}, 6$ months: $123.0 \pm 17.7 \mathrm{~cm}^{2}$ ) (Figure 4).

In relation to the delta thigh muscle area, the univariate regression analysis on each variable included lesion location, sex, baseline $\mathrm{HbA} 1 \mathrm{c}$ levels, $\mathrm{BMI}$, presence of hypertension $(\mathrm{HT})$, dyslipidemia (DL), chronic kidney diseae (CKD), and past smoking history. The variables entered in the multivariate regression model were those with a relation in the univariate analysis $(p \leq 0.10)$, revealing that the baseline $\mathrm{HbA} 1 \mathrm{c}$ was the only factor correlated with the delta muscle area of the thighs after 3 months $\left(-7.3 \mathrm{~cm}^{2}\right.$ to $-0.2 \mathrm{~cm}^{2}$ per HbA1c 1 increase, $p=0.04)$ and 6 months $\left(-10.1\right.$ to $-0.4 \mathrm{~cm}^{2}$ per HbA1c 1 increase, $\left.p=0.036\right)$ (Table 3$)$.

When the patients were categorized as either normoglycemic $(\mathrm{HbA} 1 \mathrm{c}<6.5, \mathrm{n}=16)$ or diabetic $(\mathrm{HbA} 1 \mathrm{c} \geq$ $6.5, n=6$ ) based on their baseline glucometabolic status according to the classification of the American Diabetes Association, there was no significant difference in clinical characteristics between the two groups (Table 4). Notably, the muscle area of the thighs significantly increased (before: $246.1 \pm 33.5 \mathrm{~mm}^{2}$, before vs 3 months: $249.6 \pm 34.6 \mathrm{~mm}^{2}, \mathrm{p}^{*}=0.032$, before vs 6 months: $\left.250.6 \pm 35.7 \mathrm{~mm}^{2}, \mathrm{p}^{\star \star}=0.046\right)$ in normoglycemic patients, while there was no significant alteration in hyperglycemic patients $(\mathrm{HbA} 1 \mathrm{c} \geq 6.5)$ (before: $225.2 \pm 43.4 \mathrm{~mm}^{2}, 3$ months: $224.6 \pm 44.8 \mathrm{~mm}^{2}, 6$ months: $222.2 \pm 45.5 \mathrm{~mm}^{2}$ ) (Figure 5).

\section{Discussion}

The key findings in the present study are as follows: first, PAD induces thigh muscle atrophy and EVT can restore it. The increment in thigh muscle area in the ischemic limbs after EVT, but not in the non-ischemic limbs in patients with ipsilateral PAD, supports the result. Second, the glycated hemoglobin level was negatively correlated with the change in thigh muscle area. Increases in the thigh muscle area after EVT are more pronounced in normoglycemic patients than in diabetic patients.

The loss of skeletal muscle is a growing field of medical interest since the recognition is indispensable for evaluating the disease morbidity and mortality [1]. In PAD patients, pathological analysis on the gastrocnemius skeletal muscle of patients revealed ischemic myopathy due to apoptosis [15]. Two-thirds of PAD patients had multiple lesions [8], most frequently located in the superficial femoral arteries $[16,17]$. 
Because the superficial femoral arteries vascularize the calf muscles, the assumption of a direct negative effect of PAD on the calf muscle area is reasonable [18]. More specifically, patients with proximal lesions had a poorer prognosis than those with distal lesions [19].

In PAD patients, chronic repetitive ischemia induces metabolic changes in ischemic muscle that leads to alterations in muscle structure, and eventually atrophy. In the muscle tissue of patients with PAD, mitochondrial dysfunction is found, which comprises mitochondrial respiration, subsequent poor energy production by the mitochondria, increased oxidative stress, and a significant amount of generated reactive oxygen spices (ROS), limiting exercise performance in patients with PAD [5]. Even after the successful revascularization operations and normalization of hemodynamic parameters in PAD patients, only mild improvement in a significant mitochondrial bioenergetic defect was observed [20]. Although the phenomenon observed in the previous report may conflict with our results, we showed that the thigh muscle area significantly increased after EVT. Although we did not measure the burden of ROS, muscle volume could be restored by EVT in a selected population. Enrolled patients had relatively larger stenoses than those in previous studies, and its revascularization had a larger impact on the diseased limbs [20]. The disuse of skeletal muscle, even in the short term, leads to muscle atrophy [21], and improvement of symptoms in almost all patients facilitated the use of the thigh muscles which contributed to the muscle restoration in the present study. If EVT has the capability of modifying increased ROS production and mitochondrial function defects, which attracts clinical attention since the main factor in the theory that ROS is associated with degenerative disease and aging. Furthermore, the selection of patients might have had an impact on the results.

In the present study, since the PAD patients with more proximal lesions of above the knee of iliac, femoral, and popliteal arteries were enrolled [15], the negative association between PAD and change in the thigh muscle area was elucidated. The findings of the present study were in line with those of a previous reports wherein diabetic patients were at risk of losing their skeletal muscle mass [2, 22]. In another study, a large numbers of PAD patients suffered from peripheral neuropathy complicated with diabetes, which led to immobility losing their skeletal muscle [20]. Immobilized PAD patients do not move and consult a doctor until the symptoms are aggravated to the level of ulceration with ischemic paint at rest [23]. EVT is beneficial in a selected PAD population (such as in this study) without apparent immobility who are in the relatively early stage of PAD with proximal lesions.

The prevalence of diabetes is higher in PAD patients [24], and diabetes itself is associated with excessive loss of skeletal muscle tissue [2]. However, early intervention would either stop or at least delay the loss of skeletal muscles which may have beneficial effects in patients with PAD. This study will help to pave the way for other randomized clinical trials investigating the true role of EVT in patients with intermittent claudication resulting from proximal PAD lesions [25].

This study had several limitations. First, this study was preliminary and was conducted with small number of patients. Since this study was statistically underpowered due to slow recruitment and single-centered nature, a larger number of patients enrolled in multiple centers would unveil considerably more robust information concerning PAD patients. Secondly, the observational period was 6 months, which was 
relatively short. It is necessary to observe over a longer period to assess whether the effects of EVT continue. Thirdly, we excluded patients solely with below the knee lesions and patients who were receiving maintenance hemodialysis, in whom the impact of EVT on muscle volume is not clear. Fourthly, most of the patients were male. We recommend including a larger number of patients, as well as an equal proportion of both sexes in future studies.

\section{Conclusions}

PAD induces thigh muscle atrophy, which can be restored by EVT, specifically in normoglycemic patients. This preliminary study would pave the way to establish the favorable role of EVT on the skeletal muscle indicated the need of large-scale trial.

\section{Abbreviations}

$\mathrm{ABI}$, ankle brachial index

ACE-I, angiotensin-converting enzyme inhibitor

ARB, angiotensin-II receptor blocker

BMI, body mass index

$\mathrm{Cl}$, confidence interval

CKD, chronic kidney disease

$\mathrm{CT}$, computed tomography

DL, dyslipidemia

DL, dyslipidemia

EVT, endovascular treatment

HbA1c, glycosylated hemoglobin

$H T$, hypertension

$H T$, hypertension

PAD, peripheral artery disease

ROS, reactive oxygen spices

SD, standard deviation 


\section{Declarations}

\section{Ethics approval and consent to participate}

The institutional review board of the Nippon Medical School Chiba Hokusoh Hospital approved this study and informed consent was obtained from all patients. This study had been performed in accordance with the Declaration of Helsinki obtaining informed consent from all patients.

\section{Consent for publication}

Not applicable.

\section{Availability of data and materials}

The datasets used and/or analysed during the current study are available from the corresponding author on reasonable request.

\section{Competing interests}

The authors declare that they have no competing interests.

\section{Funding}

None.

\section{Authors' contributions}

MK, HK, MT, TI, MM, NK, KA: conception and design, analysis and interpretation of data, drafting of manuscript. YM, YS, and WS: conception and design, revision of manuscript. All authors read and approved the final manuscript.

\section{Acknowledgements}

We thank all the staff of Nippon Medical School Chiba Hokusoh Hospital Cardiovascular Center for their valuable therapeutic and technical support.

\section{References}

1. Bauer J, Morley JE, Schols A, Ferrucci L, Cruz-Jentoft AJ, Dent E, Baracos VE, Crawford JA, Doehner W, Heymsfield SB et al: Sarcopenia: A Time for Action. An SCWD Position Paper. J Cachexia Sarcopenia Muscle 2019, 10(5):956-961.

2. Park SW, Goodpaster BH, Lee JS, Kuller LH, Boudreau R, de Rekeneire N, Harris TB, Kritchevsky S, Tylavsky FA, Nevitt M et al: Excessive loss of skeletal muscle mass in older adults with type 2 
diabetes. Diabetes Care 2009, 32(11):1993-1997.

3. Weitz JI, Byrne J, Clagett GP, Farkouh ME, Porter JM, Sackett DL, Strandness DE, Taylor LM: Diagnosis and treatment of chronic arterial insufficiency of the lower extremities: a critical review. Circulation 1996, 94(11):3026-3049.

4. Hirsch AT, Haskal ZJ, Hertzer NR, Bakal CW, Creager MA, Halperin JL, Hiratzka LF, Murphy WR, Olin JW, Puschett JB: ACC/AHA 2005 Practice Guidelines for the management of patients with peripheral arterial disease (lower extremity, renal, mesenteric, and abdominal aortic). Circulation 2006, 113(11):e463-e654.

5. Brass EP, Hiatt WR: Acquired skeletal muscle metabolic myopathy in atherosclerotic peripheral arterial disease. Vascular Medicine 2000, 5(1):55-59.

6. Lee SJ, Janssen I, Heymsfield SB, Ross R: Relation between whole-body and regional measures of human skeletal muscle. Am J Clin Nutr 2004, 80(5):1215-1221.

7. Marquis K, Debigaré R, Lacasse Y, LeBlanc P, Jobin J, Carrier G, Maltais F: Midthigh muscle crosssectional area is a better predictor of mortality than body mass index in patients with chronic obstructive pulmonary disease. American journal of respiratory and critical care medicine 2002, 166(6):809-813.

8. Aboyans V, Desormais I, Lacroix P, Salazar J, Criqui MH, Laskar M: The general prognosis of patients with peripheral arterial disease differs according to the disease localization. J Am Coll Cardiol 2010, 55(9):898-903.

9. Sundaram V, Bloom C, Zakeri R, Halcox J, Cohen A, Bowrin K, Briere JB, Banerjee A, Simon DI, Cleland JGF et al: Temporal trends in the incidence, treatment patterns, and outcomes of coronary artery disease and peripheral artery disease in the UK, 2006-2015. Eur Heart J 2019.

10. Ma KF, Berends B, Vedder IR, Levolger S, Gupta M, Schuurmann RC, de Vries J, Bokkers RP: Quantification of muscle mass in the legs of patients with peripheral arterial occlusive disease: associations between volumetric and cross-sectional single-slice measurements for identification of atrophy and focal sarcopenia. J Cardiovasc Surg (Torino) 2019, 60(6):672-678.

11. Bernard S, LeBlanc P, Whittom F, Carrier G, Jobin J, Belleau R, Maltais F: Peripheral muscle weakness in patients with chronic obstructive pulmonary disease. Am J Respir Crit Care Med 1998, 158(2):629634.

12. Greenland P, Abrams J, Aurigemma GP, Bond MG, Clark LT, Criqui MH, Crouse JR, 3rd, Friedman L, Fuster V, Herrington DM et al: Prevention Conference V: Beyond secondary prevention: identifying the high-risk patient for primary prevention: noninvasive tests of atherosclerotic burden: Writing Group III. Circulation 2000, 101(1):E16-22.

13. Pena EA, Slate EH: Global Validation of Linear Model Assumptions. J Am Stat Assoc 2006, 101(473):341.

14. Champely S, Ekstrom C, Dalgaard P, Gill J, Weibelzahl S, Anandkumar A, Ford C, Volcic R, De Rosario H, De Rosario MH: Package 'pwr'. R package version 2018:1-2. 
15. Mitchell RG, Duscha BD, Robbins JL, Redfern SI, Chung J, Bensimhon DR, Kraus WE, Hiatt WR, Regensteiner JG, Annex BH: Increased levels of apoptosis in gastrocnemius skeletal muscle in patients with peripheral arterial disease. Vasc Med 2007, 12(4):285-290.

16. Hyvarinen S: Arteriographic findings of claudication patients. Ann Clin Res 1984, 16 Suppl 41:1-45.

17. McDermott MM, Liu K, Tian L, Guralnik JM, Criqui MH, Liao Y, Ferrucci L: Calf muscle characteristics, strength measures, and mortality in peripheral arterial disease: a longitudinal study. Journal of the American College of Cardiology 2012, 59(13):1159-1167.

18. McDermott MM, Hoff F, Ferrucci L, Pearce WH, Guralnik JM, Tian L, Liu K, Schneider JR, Sharma L, Tan J: Lower extremity ischemia, calf skeletal muscle characteristics, and functional impairment in peripheral arterial disease. Journal of the American Geriatrics Society 2007, 55(3):400-406.

19. Aboyans V, Desormais I, Lacroix P, Salazar J, Criqui MH, Laskar M: The general prognosis of patients with peripheral arterial disease differs according to the disease localization. Journal of the American College of Cardiology 2010, 55(9):898-903.

20. Schunk K, Romaneehsen B, Rieker O, DÜber C, Kersjes W, Schadmand-Fischer S, Schmiedt W, Thelen M: Dynamic phosphorus-31 magnetic resonance spectroscopy in arterial occlusive disease: effects of vascular therapy on spectroscopic results. Investigative radiology 1998, 33(6):329-335.

21. Wall BT, Dirks ML, Van Loon LJ: Skeletal muscle atrophy during short-term disuse: implications for age-related sarcopenia. Ageing research reviews 2013, 12(4):898-906.

22. Gupta P, Lanca C, Gan ATL, Soh P, Thakur S, Tao Y, Kumari N, Man REK, Fenwick EK, Lamoureux EL: The Association between Body Composition using Dual energy X-ray Absorptiometry and Type-2 Diabetes: A Systematic Review and Meta-Analysis of Observational studies. Sci Rep 2019, 9(1):12634.

23. Varu VN, Hogg ME, Kibbe MR: Critical limb ischemia. Journal of vascular surgery 2010, 51(1):230-241.

24. Malmstedt J, Karvestedt L, Swedenborg J, Brismar K: The receptor for advanced glycation end products and risk of peripheral arterial disease, amputation or death in type 2 diabetes: a populationbased cohort study. Cardiovasc Diabeto/ 2015, 14:93.

25. Conte MS: Appropriate use of revascularization for claudication. J Vasc Surg 2020, 71(1):131.

\section{Tables}


Table 1. Patient characteristics

$\mathrm{n}=22$

Variables

Age, years

Male

$72.4 \pm 7.4$

Hypertension

$20(91)$

Dyslipidemia

$18(82)$

Diabetes

$19(86)$

HbA1c

$10(45)$

BMI

$6.1 \pm 0.7$

CKD

$24.4 \pm 3.5$

Past smoking history

1 (5)

$10(45)$

Ipsilateral lesion

Rutherford category of PAD

$14(64)$

1

2

3

Medications

$10(45)$

1 (5)

Dual Antiplatelet Therapy

$22(100)$

Aspirin

19 (86)

Clopidogrel

9 (41)

Cilostazol

6 (27)

Prasugrel

6 (27)

Statin

$21(95)$

Calcium channel blocker

$12(55)$

ACE-I/ARB

$22(100.0)$

$\beta$-Blocker

15 (68)

ACE-I, angiotensin-converting enzyme inhibitor; ARB, angiotensin-II receptor blocker. Data are presented as numbers (\%)

Table 2. Target lesion characteristics

Variables 30 ischemic lower limbs

Location of lesions

Iliac artery

Superficial femoral artery

Common femoral artery

Popliteal artery

Superficial + popliteal artery

TASC II classification

Type A

Type B

16 (53\%)

$9(30 \%)$

$1(3 \%)$

$3(13 \%)$

$1(5 \%)$

Type C

$17(58 \%)$

$6(20 \%)$

Type D

$2(6 \%)$

$5(16 \%)$

Stent implantation

Data are presented as numbers (\%)

$24(80 \%)$

TASC; Trans-Atlantic Inter-Society Consensus.

Table3 . Univariable and multivariable linear regression analysis results on the muscle area 


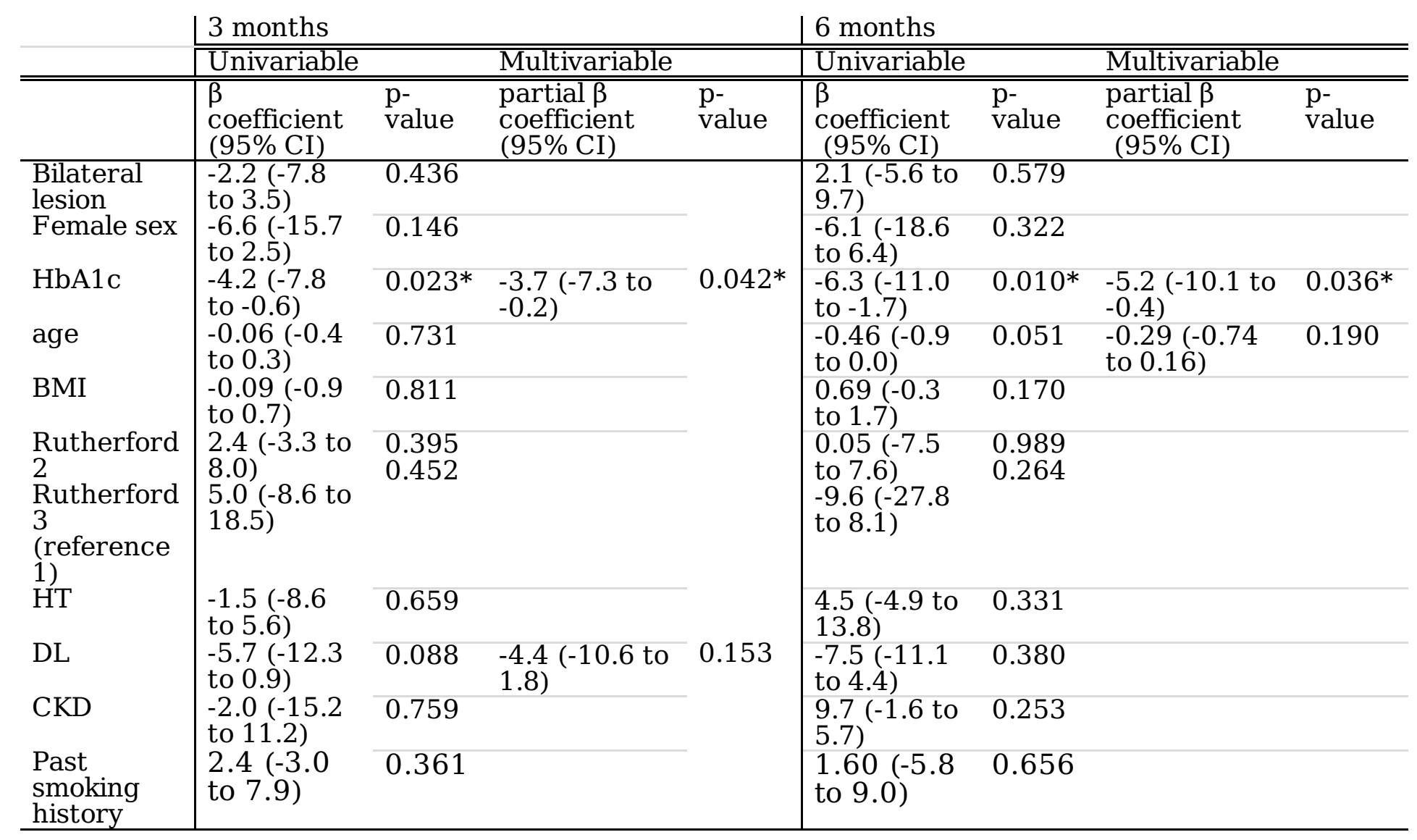

CI, confidence interval; HbA1c, glycosylated hemoglobin; BMI, Body Mass Index; HT, Hypertension; DL, Dyslipidemia; CKD, Chronic Kidney Disease, $\mathrm{p}^{*}<0.05$

Table 4. Baseline characteristics between diabetic and normoglycemic patients

\begin{tabular}{llll} 
& $\begin{array}{l}\text { Normoglycemic } \\
6.5>\mathrm{HbA} 1 \mathrm{c}\end{array}$ & $\begin{array}{l}\text { Hyperglycemic } \\
\text { HbA1c } \geq 6.5\end{array}$ & p value \\
\hline Ipsilateral lesion & $12(75 \%)$ & $2(33 \%)$ & 0.07 \\
\hline Bilateral lesion & $4(25 \%)$ & $4(67 \%)$ & \\
Female sex & $1(6 \%)$ & $1(16 \%)$ & 0.45 \\
\hline HbA1c & $5.8 \pm 0.3$ & $7.0 \pm 0.6$ & $0.0004^{*}$ \\
\hline age & $71.3 \pm 7.0$ & $75.3 \pm 8.4$ & 0.56 \\
\hline BMI & $24.3 \pm 2.3$ & $24.6 \pm 6.1$ & 0.88 \\
Rutherford & $1.56 \pm 0.63$ & $1.50 \pm 0.54$ & 0.90 \\
\hline HT & $13(81 \%)$ & $5(83 \%)$ & 0.91 \\
DL & $14(88 \%)$ & $5(83 \%)$ & 0.80 \\
\hline CKD & $1(6 \%)$ & $0(0 \%)$ & 0.53 \\
\hline Past smoking history & $8(50 \%)$ & $2(33 \%)$ & 0.48 \\
\hline
\end{tabular}

HbA1c, glycosylated hemoglobin; BMI, Body Mass Index; HT, Hypertension; DL, Dyslipidemia; HU, CKD, Chronic Kidney Disease $\mathrm{p}^{*}<0.05$ 


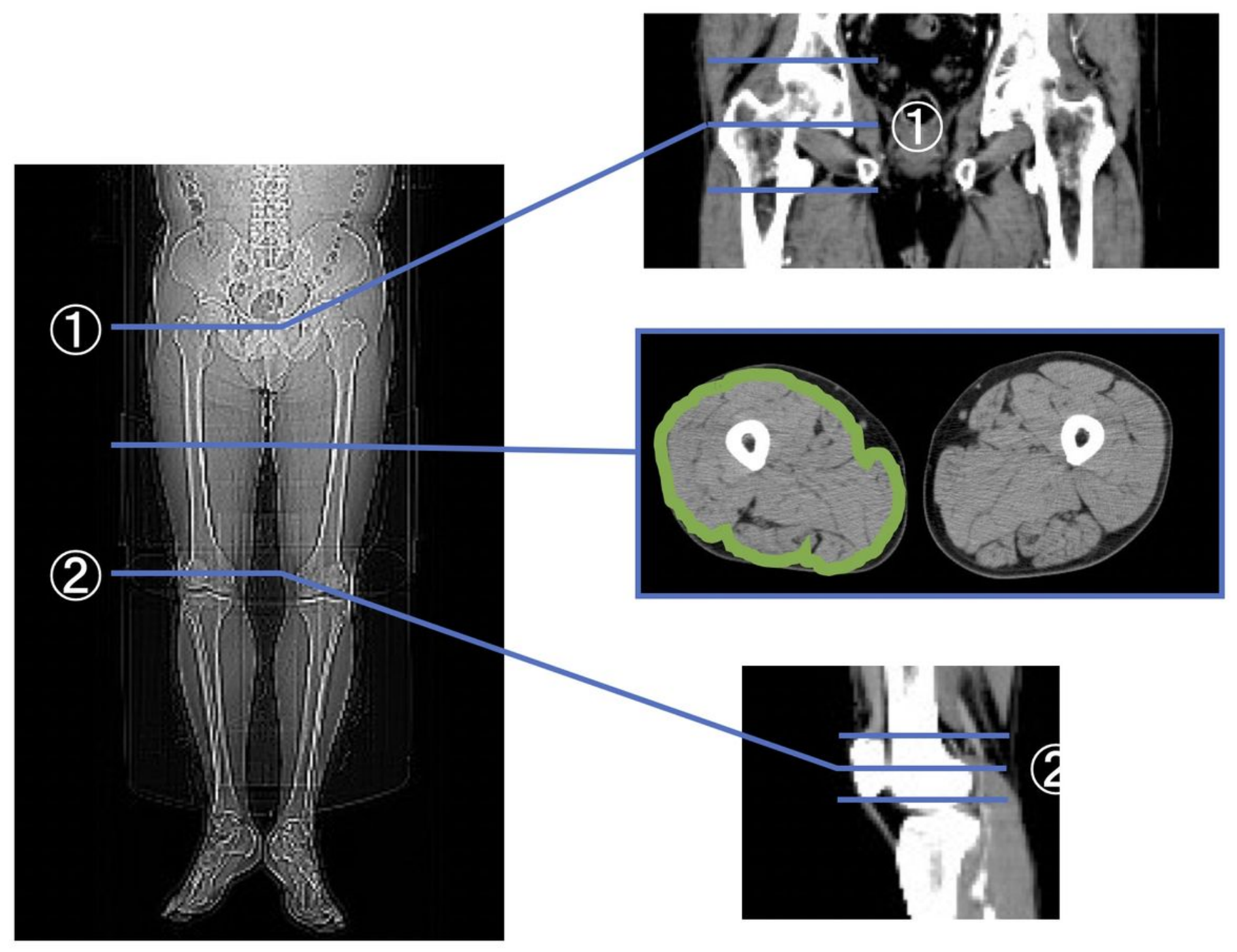

Figure 1

Measurement of the mid-thigh muscle area The thigh muscle area was measured at the midpoint cross section of 1 and 2. (1) Upper edge: midpoint of the upper margin of the greater trochanter and lower margin of the femoral condyles (2) Lower edge: midpoint of the upper margin of the patella and lower margin of the patella 
28 lower extremity PAD patients with above the knee lesions

\begin{tabular}{|l|l|} 
(Exclusions) \\
Failed EVT, $\mathrm{n}=1$ (guidewire did not cross the lesion) \\
Clinical follow up drop out, $\mathrm{n}=2$ \\
Declined consent, $\mathrm{n}=3$
\end{tabular}

\section{2 lower extremity PAD patients \\ 14 with ipsilateral lesions \\ 8 with bilateral lesions}

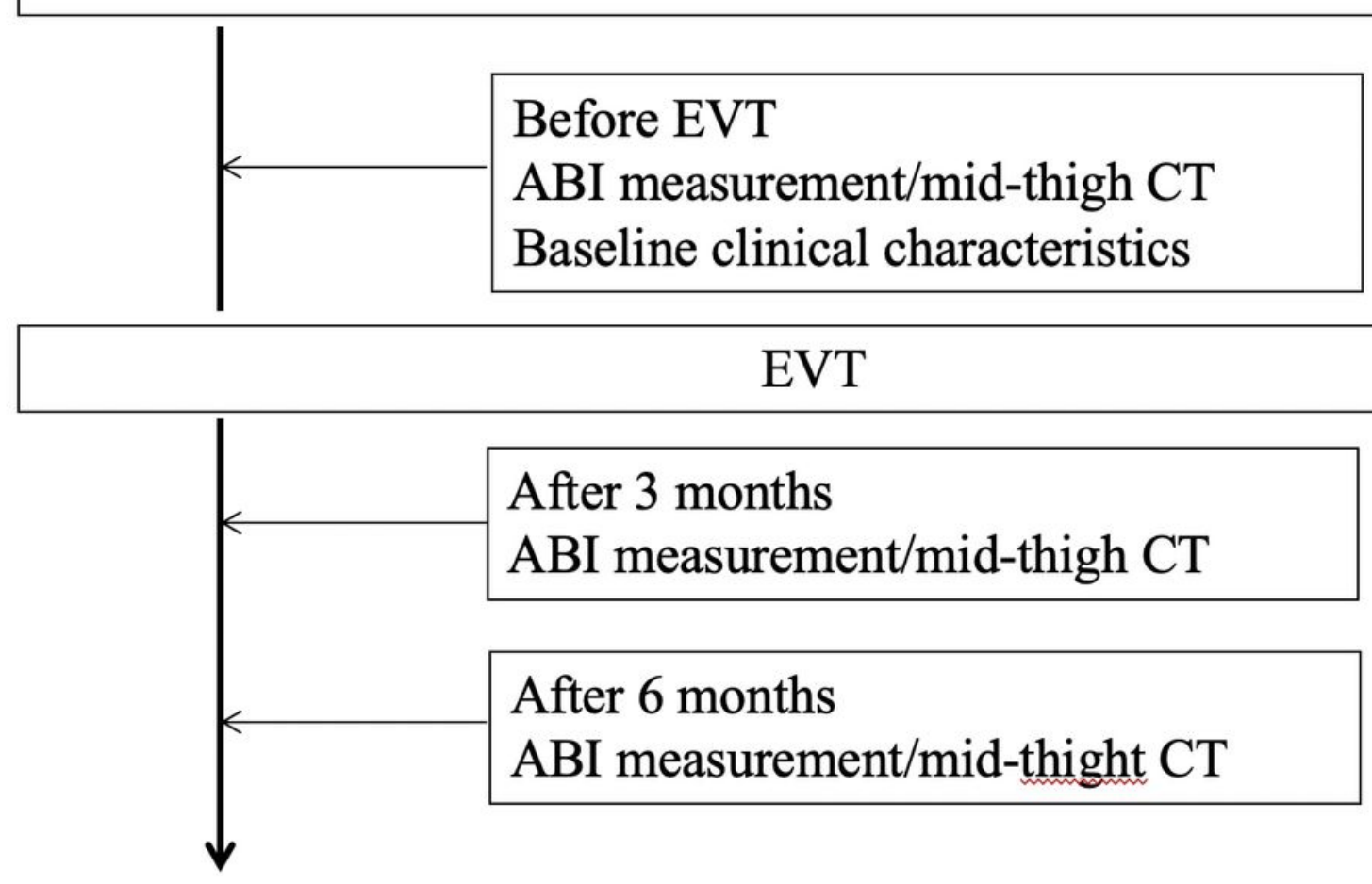

Figure 2

Study flowchart A total of 22 lower extremity PAD patients with above the knee lesions were enrolled. ABI measurement and CT scanning of the mid-thigh level of the lower limbs were performed at admission, at 3 months, and at 6 months after EVT. PAD, peripheral artery disease; $A B I$, ankle brachial index; CT, computed tomography; EVT, endovascular treatment 


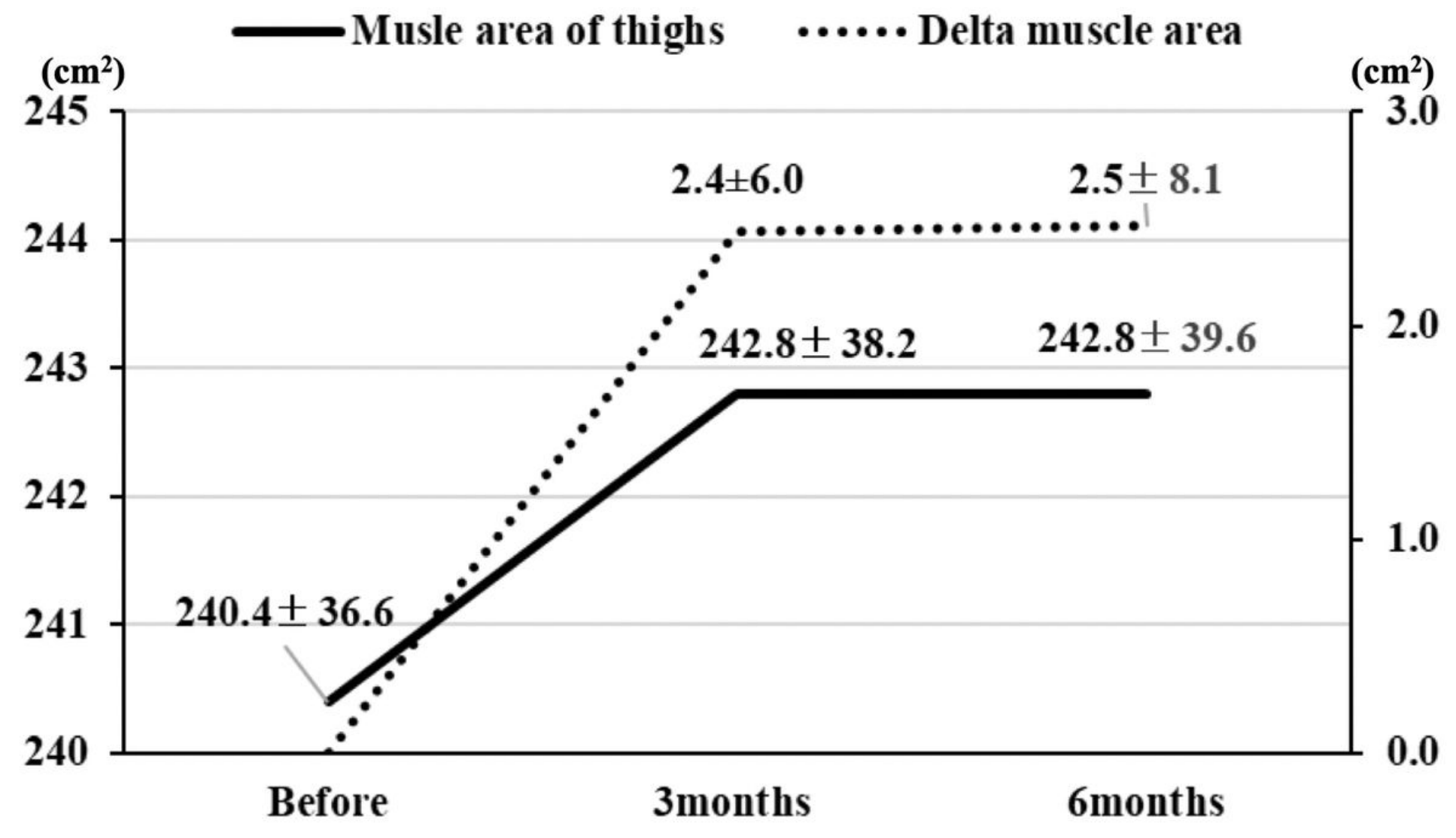

Figure 3

Change in the muscle area of the thighs On the left vertical axis, the muscle area of the thighs increased after EVT (before, $240.4 \pm 36.6 \mathrm{~cm} 2 ; 3$ months, $242.8 \pm 38.2 \mathrm{~cm} 2 ; 6$ months, $242.8 \pm 39.6 \mathrm{~cm} 2$ ). On the right vertical axis, the delta area of thigh muscles is shown (3 months, $2.4 \pm 6.0 \mathrm{~cm} 2 ; 6$ months, $2.5 \pm 8.1$ $\mathrm{cm} 2$ ). EVT, endovascular treatment 


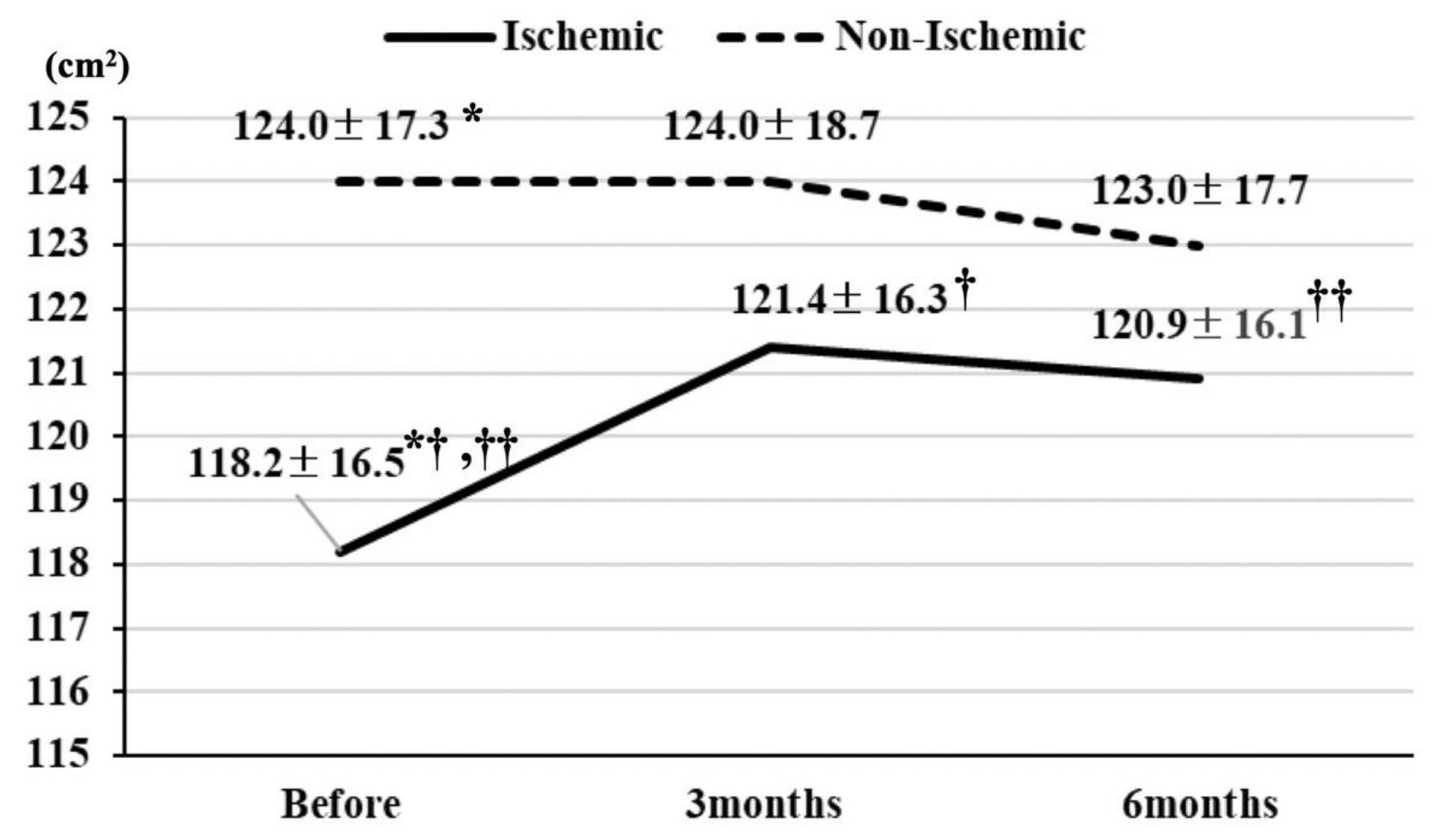

Figure 4

Change in the muscle area in patients with an ipsilateral lesion In patients with ipsilateral lesions, the midthigh muscle area of the ischemic lower limbs was significantly smaller than that of non-ischemic lower limbs $\left(118.2 \pm 16.5 \mathrm{~cm} 2\right.$ vs $\left.124.0 \pm 17.3 \mathrm{~cm} 2, \mathrm{p}^{*}=0.0002\right)$. The mid-thigh muscle area in ischemic lower limbs increased after EVT (before, $118.2 \pm 16.5 \mathrm{~cm} 2$ vs 3 months, $121.4 \pm 16.3 \mathrm{~cm} 2$, p $\dagger=0.0166$; before vs 6 months, $120.9 \pm 16.1 \mathrm{~cm} 2$, pt† $=0.0566$ ) whereas that of non-ischemic lower limbs did not (before, 124.0 $\pm 17.3 \mathrm{~cm} 2,3$ months, $124.0 \pm 18.7 \mathrm{~cm} 2,6$ months, $123.0 \pm 17.7 \mathrm{~cm} 2)$. EVT, endovascular treatment 
Normoglycemic - - Hyperglycemic

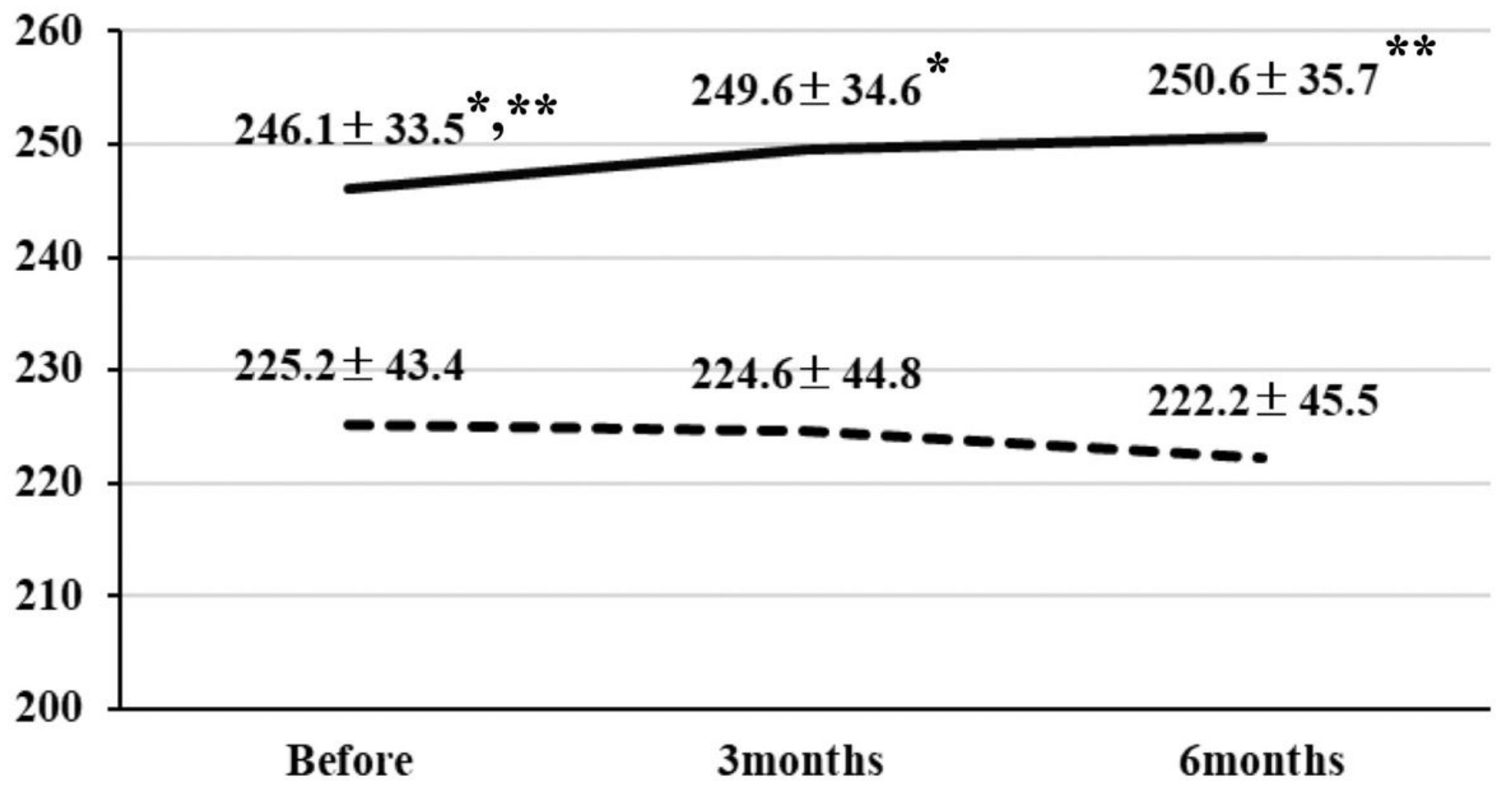

Figure 5

Change in the muscle area of thighs in patients in a glycemic condition The muscle area significantly increased in normoglycemic patients $(6.5>\mathrm{HbA} 1 \mathrm{c})$ (before: $246.1 \pm 33.5 \mathrm{~cm} 2$, before vs 3 months: $249.6 \pm$ $34.6 \mathrm{~cm} 2, p^{\star}=0.032$; before vs 6 months: $\left.250.6 \pm 35.7 \mathrm{~cm} 2, p^{\star \star}=0.0455\right)$ while there was no significant alternation in hyperglycemic (HbA1c $\geq 6.5)$ (before: $225.2 \pm 43.4 \mathrm{~cm} 2,3$ months: $224.6 \pm 44.8 \mathrm{~cm} 2,6$ months: $222.2 \pm 45.5 \mathrm{~cm} 2)$. 